\title{
La nación en tiempos neoliberales: la Marca España como brazo ideológico del gobierno
}

\author{
Alejandro Boyco Orams \\ Estudiante de Ciencia Política y Gobierno en la Pontificia Universidad Católica \\ del Perú (PUCP). e-mail: alejandro.boyco@pucp.edu.pe
}

\section{Resumen}

La marca país ha sido abordada por la academia como un fenómeno donde la construcción de la identidad nacional y la imagen externa de cada país responde a cánones y técnicas neoliberales. A raíz de la necesidad de explotar las ventajas comparativas de los países, surgen especialistas vinculados a la publicidad y al marketing, expertos en convertir la imagen nacional en una marca exportable y comercializable, asegurando el éxito en ránkings internacionales. El caso de la Marca España demuestra que el gobierno mantiene una influencia activa en la campaña publicitaria y en la construcción neoliberal de la identidad nacional. Un análisis discursivo de la campaña audiovisual en el canal oficial de YouTube de la Marca España demuestra que el mensaje transmitido responde a los objetivos e ideología del gobierno de turno y cambia en el tiempo, mientras diversos procesos políticos redefinen los fines de la política gubernamental. Estos incluyen la superación de la crisis económica, el posicionamiento de España a nivel internacional, la influencia del Estado en el Consejo de Seguridad de las Naciones Unidas y la búsqueda de unidad interna frente a movimientos separatistas catalanes. La poca autonomía de la institución administrativa encargada de la Marca España, frente al partido de gobierno, explica la alta influencia estatal en la campaña publicitaria. La Marca España no es un proceso neutral: es utilizada como un brazo político e ideológico del gobierno para alcanzar sus fines.

\section{Palabras clave}

Marca país, España, neoliberalismo, nación, identidad nacional, campaña publicitaria.

Nota editorial: el presente artículo fue recibido el 08/12/19 y aprobado el 21/01/20. 


\title{
The nation under neoliberalism: Spain's Nation Brand as an ideological arm of the government
}

\author{
Alejandro Boyco Orams \\ Political Science and Government student at the Pontifical Catholic University \\ of Peru (PUCP). e-mail: alejandro.boyco@pucp.edu.pe
}

\begin{abstract}
Nation branding has been studied in academia as a phenomenon where national identity construction and the external image of each country responds to neoliberal techniques. Following the need to exploit comparative advantages of each country, different specialists linked with publicity and marketing emerge and become experts in converting national identity into an exportable brand, assuring success in international rankings. The case of Spain's nation brand proves how the government maintains an active influence in the publicity campaign and in the neoliberal construction of the national identity. A discursive analysis of the audio-visual campaign in the official YouTube channel of Spain's nation brand proves that the message transmitted responds to the objectives and ideology of the ruling government and changes with time, while different political processes redefine the ends of the government's policy. These processes include overcoming the economic crisis, positioning Spain in the international arena, Spain's influence in the UN's Security Council, and maintaining unity against the threat of independent movements in Cataluña. The low autonomy of the administrative institution in charge of Spain's nation brand from the ruling party explains the high influence the government has in the publicity campaign. Spain's nation brand is not a neutral process: it is used as one of the government's political and ideological arms to reach its goals.
\end{abstract}

\section{Keywords}

Nation branding, Spain, neoliberalism, nation, national identity, advertising campaign. 


\section{Introducción: Neoliberalismo y marca país}

El fenómeno de la marca país aparece en un contexto donde el neoliberalismo está en auge. Los Estados, en la competencia por un mejor posicionamiento relativo a nivel internacional y en el aprovechamiento de sus ventajas comparativas, buscan explotar la imagen del propio país mediante la construcción de una marca. Este proceso también permite formar una narrativa que busca fortalecer la identidad interna y el sentido de pertenencia de los ciudadanos de dicho país. Como señala Olins (2002), la re-branderización ${ }^{1}$ es un proceso que ocurre porque la nación cambia y, con ello, se busca, también, transformar la identidad que esta representa. Sin embargo, las marcas país no existen en un vacío y no es posible un análisis al respecto sin considerar el contexto neoliberal y las técnicas que dirigen la nueva forma de construir la nación como parte de dicho fenómeno global.

Cánepa (2013) explica que la marca país, basada en las técnicas del marketing y la construcción de discursos, es una tecnología de poder que surge de la gubernamentalidad neoliberal y genera individuos homo performance, empresarios de sí mismos, quienes participan competitivamente en los retos generados por la campaña publicitaria como embajadores y operadores de la marca país. Así, la cultura de la participación ofrece la base ideológica para la gubernamentalidad neoliberal. La identidad nacional que se genera mediante la participación responde a demandas transnacionales y la ciudadanía se construye a través del consumo de los individuos a los cánones que la marca país impone.

Por otro lado, Varga (2013) demuestra que la narrativa creada por la marca país no es neutral, sino que carga tres agendas neoliberales. Por un lado, la agenda conservadora vincula la predominancia del mercado transnacional con la construcción de un discurso nacionalista y relegitima al Estado nación como un punto de identidad en un mundo globalizado. La agenda transformadora, por otro lado, desvincula el vocabulario nacionalista de la historia y la cultura, y lo vincula al neoliberalismo, flexibilizándolo y capitalizándolo. Por último, la agenda de transferencia traslada los poderes definicionales de nación a las agencias multinacionales de marketing, especializadas en marcas país, lo que privatiza un proceso que debería ser deliberativo y genera que el valor de la identidad esté en los ránkings internacionales, mas no en sí misma.

Por último, Lossio (2019) identifica cuatro imperativos neoliberales que definen a la marca país como una política cultural-neoliberal. El primero es la estrategia de márketing artístico, donde el consumo de vínculos, experiencias y emociones es una práctica social, lo cual genera lazos emocionales entre la marca y los clientes-

\footnotetext{
1 Para Varga (2013), la branderización de la nación es concebida como una estrategia publicitaria enfocada en mercados externos para establecer y comunicar una imagen específica de la identidad nacional, para aumentar exportaciones y atraer turistas, inversiones y mano de obra calificada (p. 826). El branding vincula un producto -en este caso un país- con una identidad, en la mente del consumidor, y busca afianzar el vínculo entre dicho producto y los individuos para potenciar su consumo.
} 
ciudadanos. El segundo consiste en la innovación como técnica de la marca, y enfatiza el rol del individuo al cual se atrae y fideliza. Por otro lado, se busca incrementar la reputación en un modelo centrado en la competencia y especulación. Para lograrlo, el cuarto imperativo plantea cuantificar resultados y construir una evaluación métrica que demuestre alcances y genere ránkings.

El presente ensayo busca analizar el caso de la Marca España, combinando la narrativa construida por la campaña publicitaria audiovisual a lo largo de los años y con los procesos políticos que el país atraviesa desde la creación de la marca. Así, al analizar el plano narrativo de la Marca España en su canal oficial de YouTube, junto con los procesos políticos del país y el ámbito institucional-administrativo (en tanto es parte del aparato estatal), se demuestra que, en el caso español, la marca país es utilizada como un brazo político del gobierno de turno. Tanto en la construcción de la imagen internacional como en el intento de constituir la identidad nacional, la ideología del gobierno, sus objetivos y políticas están plasmados en la estrategia y discurso de la marca. En ese sentido, la agenda de transferencia de Varga (2013) que plantea priorizar lo técnico sobre lo político, al delegar el proceso de identidad nacional a agencias multinacionales, no se cumple del todo. El gobierno de turno tendría injerencia en la campaña de Marca España y la utiliza para sus fines políticos. La visión presentada, a continuación, busca estar más relacionada con un análisis crítico de la ideología y las identidades construidas a partir de la marca, y no con la efectividad de la misma.

\section{Creación de la Marca España}

Previo a la creación formal de la Marca España, el país contaba con una imagen y reputación internacional vinculado a su historia imperial, a su atractivo turístico y a su cultura, así como con agencias encargadas de velar por ello. Aunque cada comunidad autónoma se responsabiliza por la promoción del turismo, Turespaña ${ }^{2}$ se fortalece institucionalmente, a inicios de la década de 1980, como ente nacional que transmite la imagen de lo que es España al mundo, con el principal objetivo de aumentar la atracción turística. Es en 1983 que el artista catalán Joan Miró dona a las autoridades españolas el uso de un logo de su creación: una imagen abstracta de un sol sobre las letras de España (ver Imagen 1). Enfocado en atractivos turísticos, el sol se constituyó como identidad española en los ojos del mundo, y el Sol de Miró (o el huevo frito de Miró, según algunos críticos), como el logo principal de España (Vasallo, 2003).

\footnotetext{
2 Turespaña es un organismo autónomo encargado de promover el turismo extranjero a España mediante estrategias publicitarias, con el objetivo de incrementar el gasto de turismo en el país.
} 


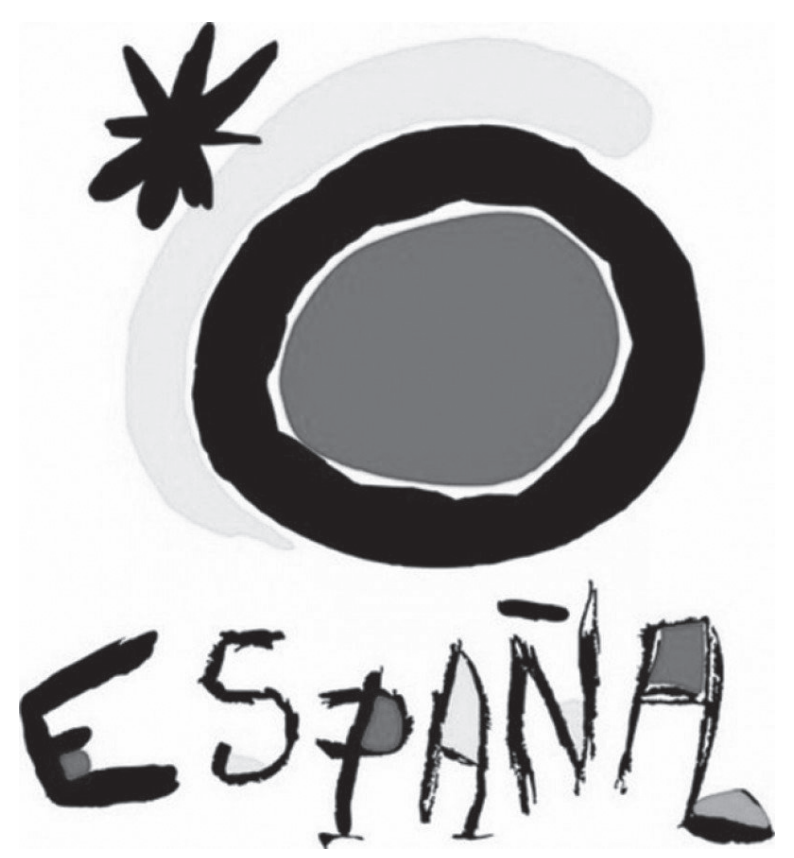

Imagen 1. El Sol de Miró. De "Hosteltur", por J. Miró, 1983,

(https://www.hosteltur.com/159130_sol-miro-celebra-30-anos-al-servicio-turespana.html)

La Marca España nace oficialmente el 12 de julio del 2012, bajo el Decreto $\mathrm{N}^{\circ} 998 / 2012$, tras algunas campañas que buscarían mejorar la imagen del país en el exterior. El recientemente nombrado presidente del Gobierno Mariano Rajoy, del Partido Popular, designa a Carlos Espinosa de los Monteros, un empresario y abogado autodenominado "ortodoxo" en visión económica, como Alto Comisionado del Gobierno para la Marca España (ACME). Los primeros meses de la creación de la marca cargan con críticas por el poco compromiso de la administración por un diseño y un concepto definido y representativo, que transmita identidad y mejore la percepción nacional.

Según anunciaron, la nueva dirección del gobierno no contaba con fondos para consultorías y asesoramiento de expertos. Las críticas argumentan que el diseño es esencial para lograr los objetivos de una marca. Como señala la Asociación Española de Empresas de Branding - AEBrand, no se trata únicamente del diseño de un logo, sino de una articulación correcta entre capacidades creativas y pensamiento estratégico, a través de un trabajo grupal multisectorial que identifique los problemas del país, las identidades buscadas y los objetivos a largo plazo (2018). Así, si bien se identifica que existe un proceso político que guía la Marca España, los procesos internos parecen carecer de diseños participativos y democráticos, ya que utilizan a técnicos para los objetivos del gobierno.

El logo de la marca España (ver Imagen 2) muestra el escudo nacional junto a "MARCA ESPAÑA", sobre un fondo rojo y amarillo. El éxito del Sol de Miró, 
basado en su carácter abstracto y en su capacidad de transmitir un mensaje de identidad, se pierde 30 años después bajo un símbolo oficial del Estado. Este nuevo logo aparece en las campañas desde la fundación de la marca, pero el Sol de Miró no desaparece del imaginario nacional.

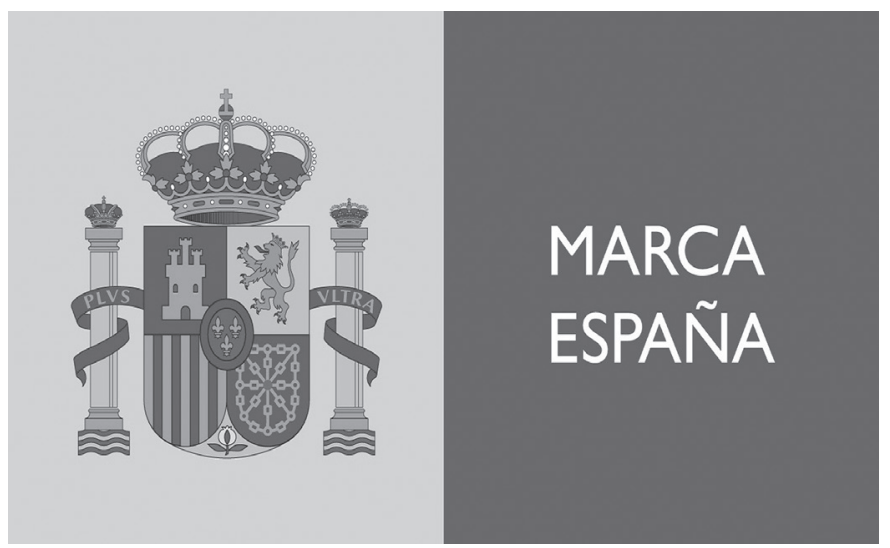

Imagen 2. Logotipo de Marca España. De "Real Academia de Gastronomía", 2012, (http:// realacademiadegastronomia.com/my-product/marca-espana-premio-nacional-gastronomia-especial/)

Parte de las razones y justificaciones de la creación de la marca es la necesidad generada por la presión de otros países y las fuerzas coercitivas del mercado internacional, que ya iniciaron dicha estrategia y consiguen ventajas sobre España, como afirma Anholt (2007). El nacimiento de la marca sucede durante el peor momento de la crisis económica del país, iniciada en el 2008, con dos objetivos: romper los prejuicios existentes contra España, cuya imagen internacional había decaído desde la recesión; y romper las dudas sobre la capacidad de los españoles de superar la crisis. Busca consolidar una imagen identitaria nacional e internacional nueva, así como superar la percepción existente al considerarla vergonzosa y como una barrera al desarrollo nacional. El discurso cambia mientras cambia la realidad, pero, sobre todo, mientras cambia la percepción. A continuación, se muestra cómo la estrategia discursiva y los objetivos de la Marca España a lo largo de los años han estado estrechamente ligados con los objetivos políticos del gobierno.

\section{España regresa a Europa}

Es así como, durante el 2012, se promueve una campaña mediática para romper con la idea de que el país debe ser salvado de sí mismo; de hecho, se muestra todo lo contrario: España representa un lugar lleno de oportunidades y con liderazgo internacional en distintos ámbitos. En línea con la ideología del gobierno y las ideas económicas del Alto Comisionado, una primera serie de campañas buscan promocionar al país como un lugar atractivo para el capital extranjero y la promoción de exportaciones, con el objetivo de recuperar la confianza internacional en España 
y convertirlo nuevamente en un país fiable y con peso internacional para atraer inversión. Prueba de esto es la publicación y difusión de una estrategia audiovisual ${ }^{3}$, que muestra los productos agroalimentarios de calidad exportados por España, las decenas de marcas multinacionales con amplio éxito mundial, y la tecnología e infraestructura de punta y de vanguardia que representan al país. La primera fase de la Marca España estuvo guiada por el interés del gobierno en superar la crisis económica con confianza internacional para atraer inversión extranjera.

Una de las fuentes de soporte para el inicio de la branderización de la marca país fue el uso de consultoras o think-tanks que exponen información sobre la situación económica de España. En el quinto aniversario de la marca, una mesa redonda del think-tank "Real Instituto Elcano" realizó una presentación durante un evento de la Marca España, donde explicó la importancia de la imagen para lograr los objetivos y políticas planteados; asimismo cómo estas fueron evolucionando durante los años ${ }^{4}$ (Real Instituto Elcano, 2015). La imagen, en tanto es una representación construida sobre la realidad, se convierte en un bien exportable. En ese sentido, para mejorar la imagen de España, se parte de estadísticas sobre la visión externa existente sobre el país, como los valores e imágenes con los que lo relacionan, la atracción para inversiones y la comparación de reputación con otros países. En resumen, las estadísticas muestran que, a nivel internacional, España es percibida como un país con buena valoración por su cultura, su lengua y su historia imperial, y que el objetivo de la marca sería combinar este tradicionalismo con la imagen de un país moderno y económicamente activo. De esta manera, la Marca España busca aprovechar los aspectos en los que el país es valorado positivamente y utilizarlos para construir la imagen que se busca transmitir: un país con tradición e historia, transformado en uno de vanguardia tecnológica y liderazgo internacional moderno. El objetivo es mostrar la capacidad del país para transformarse, y generar la confianza de que se podrá renovar, nuevamente, fuera de esta crisis, invitando a inversores a confiar en el futuro español.

Es pertinente mencionar la importancia pública que le otorga la marca país a la cuantificación de los resultados. No son pocos los anuncios sobre el éxito que tuvo un año o una campaña audiovisual, medida a través del alcance en redes sociales digitales mediante likes, comentarios, compartidos o retweets. Esto se enmarca en el imperativo de cuantificar los resultados de la estrategia. Dichos resultados se miden a través del alcance y la percepción de otros, contribuyendo al carácter especulativo de generación de valor en el neoliberalismo.

\footnotetext{
3 Todos los materiales audiovisuales utilizados para analizar la estrategia publicitaria de la Marca España en el presente ensayo se encuentran en el canal oficial de la Marca España en la plataforma digital Youtube, citado en la sección bibliográfica.

4 Afirman que la imagen construida por la Marca España mejoró la reputación (percepciones del público internacional sobre el país, complementada con la autopercepción de los ciudadanos) y esto influye en la mejora de la economía mediante inversiones, turismo y migración.
} 
Una serie de estudios sobre las marcas país en países post soviéticos, donde Nadia Kaneva (2012) es de las principales académicas, muestran el uso del branding para apoyar las transiciones políticas a través de la identidad. Estos países, que por décadas han consolidado su identidad alrededor de simbología comunista, buscan "regresar a Europa". Así, identifica, no necesitan una nueva narrativa política, sino una reconstrucción de la identidad nacional bajo nuevos ideales, con la identidad nacional reinventada mediante objetivos aspiracionales, más allá de lo comercial.

El caso de España se diferencia sustancialmente de países como Bulgaria o Romania, en tanto el proyecto anti-liberal español y su posterior transición que culmina en la década del 70. Sin embargo, es importante este caso para ejemplificar cómo, incluso, si el objetivo a corto plazo es atraer inversiones y reactivar la economía, el fenómeno de nation branding contiene cargas ideológicas e identitarias del país al cual representa. Identificar estas identidades no es un proceso natural, sino, más bien, un proceso discursivo. En el caso español, dicho proceso parte de la interacción entre la imagen nacional en el extranjero, la autopercepción de los mismos ciudadanos y el mensaje que tienen como objetivo las élites que manejan la campaña. Esto es inseparable de los objetivos del gobierno de turno y de la coyuntura: reinsertarse en Europa como un centro económico y con peso político regional. El "retorno a Europa", presente en los países post comunistas está, de alguna manera, presente en España como su objetivo.

\section{España, país de talento}

Una vez recuperada la percepción positiva del país y con la economía en crecimiento, era momento de una estrategia dirigida al autoestima de la ciudadanía. Así, un lado más humano de la estrategia de la marca país surge con el spot del 2013, denominado Innovadores y Plurales: un lugar donde cabemos todos (España Global). Este cambio discursivo no llega a romper con el matiz economicista de la primera fase, pero introduce al ciudadano español como agente en la construcción de esta retórica. Era este ciudadano quien había conseguido transformar a su país de manera radical, a través del esfuerzo y el trabajo, en dos momentos: la transición democrática con la caída del franquismo y la superación de la crisis económica del 2012. Sin embargo, este mensaje es parcialmente instrumentalizado para continuar con la atracción de capitales e inversores. De esa forma, la crisis económica redujo los precios y con la recuperación se abrieron facilidades para inversores y turistas, así como para ampliar el mercado y generar espacios de competencia.

Es en este primer spot donde se hace presente la construcción de un perfil de ciudadanía. Esto ocurre, por un lado, a través de la mención a la diversidad cultural, histórica y de lenguas, al tomar las diferencias presentes entre culturas y comunidades autónomas como un valor esencial de España. Por otro lado, el reconocimiento oficial a embajadores que han dejado en alto el nombre de España, a lo largo de sus vidas, permite que la población se reconozca, también, en ellos y se genere un sentido de 
pertenencia. Junto con esta variable humana se incrementa, también, la mención e importancia de ámbitos en donde España lidera a nivel regional o mundial, como la manufactura, energía renovable y sostenibilidad, moda, así como la tecnología sanitaria y médica; pero, esta vez, con un mensaje que resalta el capital humano innovador detrás de estos logros.

Esta combinación de talento humano y liderazgo continúa con los años, mientras la economía se recupera, y la autoestima y la percepción externa mejoran. El spot del 2016, Todos hacemos Marca España (España Global, 2016a), ubica en el centro del mensaje a las futuras generaciones como agentes de cambio y al trabajo en equipo como modelo a seguir. La invitación al espectador de formar parte del proyecto nacional es explícita y clara. Bajo la frase de "Nuestra diversidad nos hace fuertes" es que se vuelven a poner sobre la mesa las fortalezas del país a nivel internacional, aunque se nota, aún más, la transición hacia lo humano, al introducir temas como la alta esperanza de vida, referentes en trasplantes infantiles, investigación médica y su rol en ayuda humanitaria internacional.

Gran parte de la campaña ha sido mostrar al mundo lo que España exporta y ha exportado, más allá de los bienes materiales y agroalimentarios. Este ejemplo se muestra en varios discursos sobre el "descubrimiento del nuevo mundo", en los que se jactan de exportar cultura, lenguaje y arquitectura a toda Latinoamérica. Diversas campañas resaltan la presencia de ciudadanos españoles en el extranjero (España Global, 2017a) o el rol de la avanzada industria de infraestructura en grandes proyectos mundiales como el Canal de Panamá y la tecnología para el control aéreo (España Global, 2016b). Sin embargo, hay un hito que comprueba el éxito inicial de la estrategia de Marca España en la percepción internacional y que marcará una etapa menor en su campaña publicitaria sobre lo que España contribuye al mundo.

Desde el 1 de enero de 2015, España se convierte en miembro no permanente del Consejo de Seguridad de la ONU (CSNU). Esto refleja que la percepción externa sobre España y su solidez y peso en la comunidad internacional había cambiado positivamente desde el 2012. A partir de este evento, gran parte de la estrategia de la Marca España se centra en comunicar sus logros y contribuciones a la comunidad internacional. Así, el discurso vuelve a mencionar la superación, esfuerzo y transformación como valores intrínsecos de España. Por otro lado, durante su membresía y una vez finalizada esta, un conjunto de mensajes audiovisuales publicados en la misma cuenta de YouTube recalcan los logros del país con respecto a la lucha contra el terrorismo, desminado, multilateralismo, ciberseguridad, igualdad de género, etc. Pertenecer al CSNU contribuye con los objetivos de la marca país de mejorar la percepción interna y externa de España. De la misma manera, la marca país puede ser utilizada como parte de la diplomacia internacional y el soft power (Jiménez-Martínez, 2013), que permitirían al Estado influir en otras en instancias, como en el mismo CSNU. Estudios de las relaciones internacionales presentan la 
reputación de un país y su imagen a los ojos de vecinos regionales como un factor fundamental de influencia, jerarquía y poder. En palabras de Gilboa (2001, p.2), la imagen y el control de flujos de información de un país o un líder permiten determinar su estatus en la comunidad internacional.

\section{España diversa, pero con eñe}

Es en el 2015 cuando se puede observar una consolidación estructurada de los mensajes iniciales descritos en la fase anterior bajo un nuevo spot publicitario: Todo lo que esperas y mucho más de lo que te imaginas (España Global, 2015c), el primer anuncio traducido al inglés, francés y alemán. Esto marca el inicio de una fase paralela a la anterior descrita, con un mensaje implícito de homogenización interna $y$, por consiguiente, exclusión propiciado por objetivos político. En este spot se invita al espectador a "descubrir España", descrito a través de sus siglas como "Empresa,

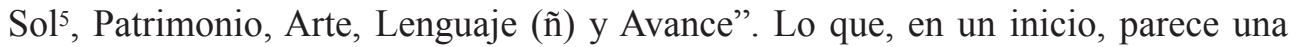
promoción del turismo y la inversión, luego construye, en realidad, una imagen del país, desagregada en seis componentes que representan lo económico-tecnológico, lo humano, lo histórico-tradicional y la identidad colectiva de los ciudadanos bajo el idioma español. Esto último es un importante giro que rompe con los breves intentos de fortalecer la diversidad lingüística y cultural como identidad española generados en las campañas iniciales.

Es desde este momento en que el idioma español se vuelve, bajo el discurso de la Marca España, un elemento constitutivo de la identidad española. Otra serie de videos que premian y refuerzan el talento humano en distintos sectores se caracteriza por tener la virgulilla $(\sim)$ como símbolo central (España Global, 2015b; España Global, 2016c). Si bien no es un elemento único del español, este cambio y símbolo vienen acompañados de un discurso identitario que se vuelve más presente en la propaganda de Marca España mientras pasan los años. Un tuit de la cuenta oficial de Marca España muestra la inauguración de una escultura con dicha virgulilla, acompañado del texto "La escultura representa la virgulilla de la Ñ las olas del mar y la capacidad de superación de los españoles" (España Global, 2015a).

El spot publicitario El español: lengua global (España Global, 2018a), de enero del 2018, inicia con una narración que invisibiliza la diversidad lingüística del país: "Somos diversos, dispares, vivimos en diferentes países, pero tenemos algo en común: nos entendemos. Hablamos, escribimos, pensamos, programamos y sentimos en español. [...] Es la llave del futuro y la esencia de la Marca España." Esto sugiere tener una doble intención. Por un lado, está el interés político en unificar la identidad española para reducir los nacionalismos periféricos dentro del territorio, a pesar de la aparente contradicción con la importancia de la diversidad como valor

5 Este componente demuestra cómo el Sol de Miró consolidó el mensaje de Sol en las futuras campañas promocionales del país. 
sustancial de la nación. Por otro, sigue una lógica neoliberal al branderizarse el país: el idioma español, al tener 550 millones de hablantes, es exportable por la demanda internacional, presionados por su expansión natural y sin una mayor preocupación por las identidades menores o no hegemónicas. Esto es parte de la transnacionalización de la identidad que veremos a continuación.

Al observar todas las campañas de la Marca España en su conjunto, se observa que, fuera de los primeros videos donde explicitan la existencia de idiomas presentes en España distintos al español, la presencia de distintas identidades dentro del territorio es casi inexistente en la concepción de esta marca país. En el 2017, hay un cambio de estrategia sutil, donde el material audiovisual surge con más frecuencia, con videos de menos duración y con mensajes menos vinculados a una gran identidad española. Quizás por haber conseguido la estabilidad económica que buscaron en un inicio, el prestigio internacional y haber mejorado en la autoestima es que se da este cambio. Es en este grupo de campañas que surgen dos vinculadas a las comunidades autónomas. Una es por el día de las letras Gallegas, con los poemas de Rosalía de Castro (España Global, 2017b), y el segundo se trata de un pequeño video rindiendo respeto a las víctimas de un atentado terrorista en Barcelona, titulado No tinc por (No tengo miedo) (España Global, 2017c).

La ciudadanía nacional que se busca articular, a través del discurso del idioma español, es una que limita o invisibiliza a las culturas tradicionales minoritarias, pero, de igual manera, como se verá a continuación, es una ciudadanía global e integrada a lo transnacional. Sobre las decisiones políticas que están detrás, es importante agregar que la agencia encargada cambió de nombre en el 2018 para llamarse "Alta Comisión para la Marca España y la promoción del idioma español", lo cual evidencia la intencionalidad detrás de la priorización del idioma español como parte de la identidad Española ${ }^{6}$.

\section{España global}

El cambio más radical en la estrategia de Marca España ocurre en el 2018 y sucede por una decisión política, nuevamente. El 2 de junio de este año, Mariano Rajoy pierde la campaña por la presidencia ante Pedro Sánchez del Partido Socialista Obrero de España (PSOE). Un tiempo después, Sánchez nombra a Irene Lozano, política con vínculos al PSOE, como líder de la nueva Secretaría de Estado de la España Global del Ministerio de Asuntos Exteriores, Unión Europea y Cooperación Internacional. Así, la Marca España se reformula en España Global, con un nuevo logo, mensaje, liderazgo y posición administrativa institucional. Lozano admite que esto significa, también, un cambio de política, que priorizará los aspectos culturales

\footnotetext{
6 Es comparable al proceso ocurrido durante la dictadura franquista Española, donde se ilegaliza el idioma catalán. La diferencia es que ahora la primacía del idioma español se impone mediante mandatos neoliberales y con mayor sutileza, sin el autoritarismo estatal y militar presente.
} 
y políticos por sobre los económicos (Ramón, 2018), ya que los resultados de la Marca España, aunque positivos, se centran mucho en gastronomía y turismo. El nuevo logo simboliza una esfera con colores representativos, lo que transmite la influencia de España en el mundo: su transnacionalización.

En una comparación similar al logo del 2012, las críticas abundaron por la manera de conformar el cambio de marca país. La misma AEBrand denunció su preocupación por el súbito cambio de estrategia y la intromisión del nuevo gobierno en la campaña. El logo estuvo a cargo de Myriam Maneiro, artista creativa española que donó su talento para la creación de la imagen (ver Imagen 3). El que, una vez más, haya sido una donación, esta vez por la falta de presupuesto asignado a la secretaría por haber sido creada con poca anterioridad, generó críticas hacia el compromiso del gobierno con la marca país. Sin embargo, se evidencia, otra vez, la poca autonomía que Marca España tiene con respecto al gobierno de turno: ambas personas que han liderado la agencia encargada de la marca fueron designadas por el gobierno como un cargo de confianza y, por consiguiente, responderán a la agenda de dicho gobierno.
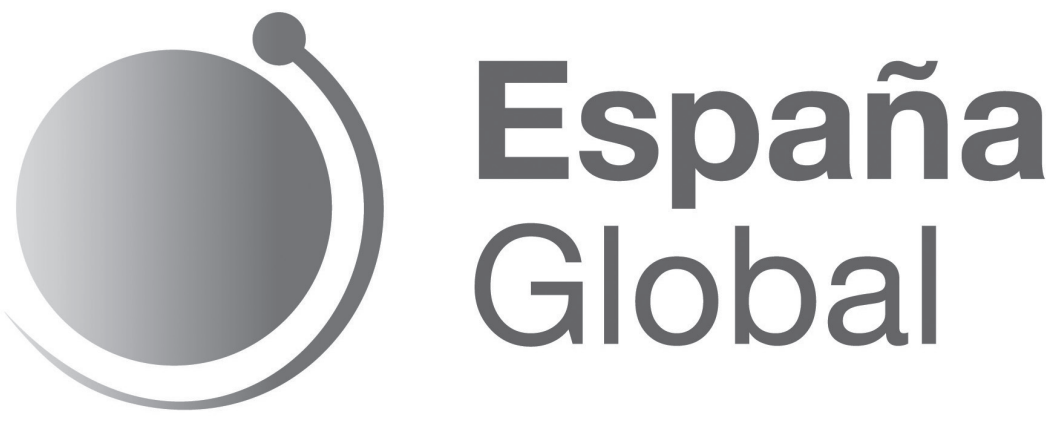

Imagen 3. Logotipo de España Global de M Maneiro. De "Ministerio de Asuntos Exteriores, Unión Europea y Cooperación”, 2018, (http://www.exteriores.gob.es/Consulados/HONGKONG/es/ Consulado/Documents/logo\%20Espa\%C3\%B1a\%20Global-01.jpg)

Si bien es muy pronto para ahondar en el cambio de estrategia o en los resultados que esta trae, es evidente el cambio de discurso, aunque también la continuidad de otros aspectos. Un primer spot, Eres España Global (España Global. 2018c), enfatiza los liderazgos del país en varios sectores, pero incluye factores políticos no mencionados por la Marca España. Siguiendo la línea trazada por las fases previamente expuestas en el presente texto, se podría afirmar que esta es la fase más humana, centrándose en aspectos como el sistema sanitario eficiente, la donación y trasplante de órganos, la publicación de artículos científicos, la comunicación, la aceptación a la comunidad LGBT y, con mayor énfasis, el nivel de democracia (Abellán, 2018). En una línea similar, This is the real Spain (España Global, 2018b) fue otro spot que aplicó incluso mayor profundidad sobre la calidad de la democracia, en el cual se explicita su desarrollo histórico, la comparación regional y mundial, su vínculo con la paz, y haciendo énfasis en la diversidad de lenguas y culturas dentro 
del estado español. Al respecto, Irene Lozano7 afirma lo siguiente: "mucha gente quiere levantar fronteras y muros, entre los países y dentro de los países, sirviéndose de mentiras, reinterpretaciones y noticias falseadas $[. .$.$] no podemos permitirnos que$ se destruyan consensos sobre lo que significa la 'libertad', la 'democracia', sobre lo que significa decidir en un país democrático” (La Moncloa, 2018).

En ese sentido, surgen algunas apropiaciones de la marca y usos de sus slogans a manera de crítica. Una página web de anónimos denominados Spanish Police (2017) utiliza el hashtag \#ThisIsTheRealSpain y muestra 805 videos de la represión policial al proceso de referéndum en octubre del 2017, como respuesta a la campaña con el mismo nombre que realza la democracia del país. Un canal catalán de YouTube, Òmnium Cultural, republica el audio del video oficial de la misma campaña, con texto en catalán e imágenes de la represión policial, los movimientos franquistas, una crítica a los toreros, la corrupción de sus políticos, la pobreza y el recorte de impuestos a los ricos, los feminicidios, y la crisis migratoria; todo ello como una crítica directa a los mensajes mostrados por el spot original (2019). Por otro lado, diversos medios independientes realizan un fact check a los mensajes de España Global e Irene Lozano, y muestran que muchas veces los ránkings publicados, la data y los anuncios sobre los indicadores democráticos no son del todo ciertos. Siendo la democracia uno de los principales pilares de España Global, las críticas demuestran que la campaña de la marca país busca su cometido faltando a la verdad ${ }^{8}$.

Así, diversos movimientos, sobre todo catalanes e independentistas, se apropian del mensaje para mostrar lo que consideran que el Estado central busca esconder de la verdadera España. Para comprender esto, es posible remitirnos al mensaje que especifica Kaneva (2011, p.202) sobre las marcas país en países post soviéticos, muy aplicable al caso español. La autora plantea que las campañas estatales publicitadas terminan por secuestrar debates internos más amplios sobre la identidad nacional y esconde la naturaleza política de la construcción de identidad. Esto ocurre por la lógica comercial que guía el branding y limita los imaginarios nacionales, mientras profundiza las crisis identitarias internas. Las campañas de marca país muestran una serie de 'atracciones' que afirman representar al país, pero realzan la conciencia que existe una diferenciación perpetua entre la imagen del self que se proyecta hacia el exterior (como objeto de consumo para el turismo y, podemos agregar, inversión), y otro self más real, distinto al proyectado.

En el intento de España, como Estado central, de proyectar una imagen unificada del país hacia el exterior, tanto como medio para cumplir ciertos objetivos internos,

\footnotetext{
7 Lozano ha hecho explícito su interés por tratar el "tema de Cataluña", luego de que el Parlamento de Cataluña y movimientos separatistas hayan impulsado un referéndum independentista que muchos han catalogado como intento de golpe de Estado y que el mismo Tribunal Constitucional declaró ilegal. Esto impulsa la intensión de mostrar lo valiosos de la democracia Española, frente a las denuncias catalanas y el desprestigio de la imagen externa del país.

8 Los rankings publicados por España Global son generados sin incluir todos los índices (como el de participación) y manipulando la estadística a su favor (ver Lluent, 2020).
} 
como fin en sí mismo de reputación internacional, construye una representación de la identidad nacional sin procesos deliberativos de imaginarios nacionales diversos. Esto, en un país tan polarizado como España, termina por dividir, aún más, a las comunidades subnacionales. Guiado por intereses políticos, pero sin mecanismos democráticos-deliberativos, la marca España sirve, también, como herramienta para criticar y minimizar la opinión pública e internacional de estos movimientos cuestionadores de la uniformidad nacional. La imagen del país se vuelve un ideal esencial para el Estado y muchos de sus ciudadanos, y defenderlo es una prioridad frente a los "disturbios" de las protestas. Así, en términos generales, no importa la realidad del país, la disconformidad de parte de la población, el reclamo de derechos o crisis internas, mientras la percepción del país a ojos externos sea positiva.

\section{Conclusión}

A modo de balance, se puede afirmar que dos grandes estrategias marcaron la Marca España, cada una relacionada al gobierno de turno, su ideología y objetivos políticos. La primera, con el Partido Popular en la presidencia, si bien varía a través de los seis años, tiene como mensaje transversal y común el objetivo de la atracción de inversiones mediante la percepción externa de confianza, fiabilidad, peso internacional y liderazgo tecnológico. Por otro lado, el cambio en la estrategia de la marca, a partir del 2018, expresa la intencionalidad del cambio de estrategia hacia una menos "económica", siguiendo el razonamiento de cambio de ideología en el gobierno y la cabeza de la agencia encargada. Sin embargo, existe una continuidad e, incluso, un reforzamiento hacia a la construcción de una identidad común, centralizada y difuminadora de las diferencias culturales, como estrategia contra las amenazas internas que ponen en riesgo la unidad nacional.

En ese sentido, la marca país española ha sido un brazo político para el gobierno, dirigido a distintos objetivos que trascienden lo técnico de la marca país y responden a necesidades políticas específicas, a través de estrategias coherentes con la ideología y forma de hacer política del gobierno de turno. Es posible afirmar que, si bien no fue ni es la única estrategia del gobierno para lograr sus cometidos, los objetivos políticos específicos de cada momento fueron alcanzados con la ayuda de la marca: fortalecer la economía, cambiar la percepción del país y, ahora, mantener un discurso de unidad frente a las amenazas internas.

El presente artículo se centró en los procesos políticos y su relación con las campañas publicitadas vía material audiovisual por el transcurso histórico de Marca España. Se requiere un mayor estudio sobre la respuesta ciudadana, ya que el proceso publicitario y mensaje del gobierno debe variar al respecto y adaptarse a amenazas o, quizás, demandas que surjan en el camino. Finalmente, la identidad no se construye únicamente desde el Estado, sin capacidad de respuesta y negociación ciudadana. Una combinación de un mensaje más político y una coyuntura y arena política-ciudadana más avivada, activa y polarizada, generó mayor presencia de 
críticas hacia España Global que a la Marca España durante el gobierno de Rajoy. Un análisis de la cuenta oficial de Twitter de la marca, activa desde el 2013 y con más de 10 mil publicaciones (sobre todo en los últimos meses) sería útil. Aquí se observa mayor interacción con la ciudadanía digital, quienes tienen capacidad de respuesta y muestran la apropiación de los mensajes y campañas para apoyar o criticar la publicidad de la marca y los mensajes que transmite.

Por último, es importante recalcar el concepto de marca país como parte del fenómeno neoliberal. El caso de Marca España, como se demostró, cumple con los imperativos culturales identificados por Lossio (2019) y con la gubernamentalidad neoliberal planteada por Cánepa (2013). Son las agendas de Varga (2013) las que no se cumplen del todo. Si bien la identidad nacional se flexibiliza y capitaliza mediante el vocabulario neoliberal, que también relegitima al Estado nación en el contexto internacional globalizado, los poderes definicionales de dicha identidad no se transfieren en su totalidad a las agencias de branding. El caso de España comprueba que la construcción de la nación, la discusión sobre la identidad nacional y la definición de ciudadanía siguen ligadas a las élites nacionales y a procesos político, mientras que el carácter deliberativo del mismo se ve reducido por las presiones de demandas externas y la necesidad de explotar las ventajas comparativas entre países. $\mathrm{Su}$ aparente neutralidad no solo es falsa al reproducir los cánones neoliberales planteados por la literatura, sino también al instrumentalizarlos para los objetivos políticos del gobierno. Parte de lo que permite que la capacidad estatal sobre la construcción de identidad nacional se mantenga presente es la poca autonomía que la institución administrativa encargada de la marca país tiene en relación al gobierno de turno. Las dos cabezas de la Alta Comisión para la Marca España fueron designadas en cargo de confianza por el partido de gobierno, lo cual asegura que la estrategia publicitaria comparta la línea ideológica de la élite política gobernante. 


\section{Referencias bibliográficas}

Abellán, L. (2018, noviembre 20). España Global se centrará en defender la calidad de la democracia española. Recuperado de https://elpais.com/politica/2018/11/19/ actualidad/1542657069 929908.html

AEBrand. (2018, noviembre 20). La falta de estatura de España Global. Recuperado de https://aebrand.org/la-falta-de-altura-de-espana-global/

Anholt, S. (2007). Competitive Identity. The New Brand Management for Nations, Cities and Regions. Nueva York: Palgrave Macmillan.

Cánepa, G. (2013). Nation Branding. The Re-foundation of Community, Citizenship and the State in the Context of Neoliberalism in Peru. Medien Journal, 37 (3),7-18.

España Global. (s. f.). Videos [Canal de Youtube]. Recuperado de https://www.youtube.com/ user/marcaespanaoficial/videos

España Global (2013, enero 17) Innovadores y Plurales - MARCA ESPAÑA [Archivo de video]. Recuperado de https://www.youtube.com/watch?v=Q1os-1oSmNg

España Global [@EspanaGlobal] (2015a, marzo 3) La escultura representa la virgulilla de la $\tilde{\mathrm{N}}$, las olas del mar y la capacidad de superación de los españoles [Tuit]. Recuperado de https://twitter.com/EspanaGlobal/status/572839005143900160

España Global (2015b, marzo 5 España Hoy.Una nueva visión del talento Español. Video Mapping [Archivo de video]. Recuperado de https://www.youtube.com/ watch?v=W0it54xp8bA

España Global (2015c, julio 13) Marca España. "Todo lo que esperas y mucho más de lo que imaginas" [Archivo de video]. Recuperado de https://www.youtube.com/ watch?v=0e5Ih4SpClY

España Global (2016a, febrero 16) Todos hacemos Marca España (2016) - MARCA ESPAÑA [Archivo de video]. Recuperado de https://www.youtube.com/watch?v=WQE1 taqffkk

España Global (2016b, junio 6) España Construye - MARCA ESPAÑA. [Archivo de video]. Recuperado de https://www.youtube.com/watch?v=DutZRMsMokY

España Global (2016c, julio 7) Video Mapping ‘España Hoy’ de Marca España, en Barcelona. [Archivo de video]. Recuperado de https://www.youtube.com/watch?v=tnOQ3GZwZxU

España Global (2017a, enero 17) Spain Everywhere, España en todo el mundo MARCA ESPAÑA [Archivo de video]. Recuperado de https://www.youtube.com/ watch? $\mathrm{v}=\mathrm{VjGbnLgHxwI}$

España Global (2017b, mayo 17) Día de las Letras Galegas - MARCA ESPAÑA [Archivo de video]. Recuperado de https://www.youtube.com/watch?v=3mpiY0jR7bA 
España Global (2017c, agosto 26) No tinc por [Archivo de video]. Recuperado de https:// www.youtube.com/watch?v=L7bpajC2x5Y

España Global (2018a, enero 24) El español, lengua global - MARCA ESPAÑA [Archivo de video]. Recuperado de https://www.youtube.com/watch?v=EtQXHVmWXCQ

España Global (2018b, diciembre 5) This is the real Spain [Archivo de video]. Recuperado de https://www.youtube.com/watch?v=RoDIINIRgis

España Global (2018c, diciembre 31) Eres España Global [Archivo de video]. Recuperado de https://www.youtube.com/watch?v=Jj6J2Pv4erY

Gilboa, Eytan. (2001). Diplomacy in the media age: Three models of uses and effects. Diplomacy \& Statecraft, 12(2), 1-28.

Graffica. (2012, octubre 25). Luz Erhardt - Saffron: «Decir que España no tiene marca es como decir que un individuo no tiene identidad». Recuperado de https:/graffica.info/luzerhardt-saffron-decir-que-espana-no-tiene-marca-es-como-decir-que-un-individuo-no-tieneidentidad/

Graffica. (2015, abril 04). ¿Qué es «marca España»? Recuperado de https://graffica.info/ que-es-marca-espana-2/

Jiménez-Martínez, C. (2013). Chile's Quest to Improve its Image Abroad. Journal of Place Branding and Public Diplomacy, 9(4), 279-290

Kaneva, N., \& Popescu, D. (2011). National identity lite: Nation branding in postCommunist Romania and Bulgaria. International Journal of Cultural Studies, 14(2), 191207. doi:10.1177/1367877910382181

Kaneva, N. (2012). Nation Branding in Post-Communist Europe: Identities, Markets, and Democracy. En N. Kanva (Ed), Branding Post-Communist Nations: Marketizing National Identities in the New Europe (pp. 3-19). New York, NY: Routledge

La Moncloa. (2018, diciembre 05). \#ThisIsTheRealSpain | Gobierno de España. [Archivo de video]. Recuperado de https://www.youtube.com/watch?v=9plTx_W2HYc\&feature=youtu.be

Lossio, F. (2019). La nación en tiempos especulativos o los imperativos culturales de las marcas país. En G. Cánepa \& F. Lossio (Eds.). La nación celebrada: marca país y ciudadanías en disputa. Lima: Red de Ciencias Sociales.

Logotipo sin título de la Marca España [Imagen] (2012). Recuperado de http:// realacademiadegastronomia.com/my-product/marca-espana-premio-nacional-gastronomiaespecial/

Lluent, È. (2020, enero 24). España Global inventa un ranking para proclamarse 13a mejor democracia. Recuperado de https://www.media.cat/2019/12/31/espana-global-rankinginexistente-democracia-derechos-humanos/ 
Maneiro, M. (2018). Logotipo de España Global. Recuperado de http://www.exteriores. gob.es/Consulados/HONGKONG/es/Consulado/Documents/logo $\% 20 \mathrm{Espa} \% \mathrm{C} 3 \% \mathrm{~B} 1 \mathrm{a} \% 20$ Global-01.jpg

Miró, J. (1983). [Logotipo sin título de Turespaña]. Recuperado de https://www.hosteltur. com/159130_sol-miro-celebra-30-anos-al-servicio-turespana.html

Olins, W. (2002). 'Branding the Nation - The Historical Context'. The Journal of Brand Management, 9(4), pp. 241-248.

Òmnium Cultural. (2019, febrero 02). This is the real Spain [CAT]. [Archivo de video]. Recuperado de https://www.youtube.com/watch?v=_bt54onooJc

Ramón, D. (2018, noviembre 19). España Global, la nueva marca del país: Economía. Recuperado de https://www.hosteltur.com/109843_espana-global-la-nueva-marca-del-pais.html

Real Instituto Elcano (2015, julio 21). España: imagen y marca 2015: ¿Cómo nos ven, cómo somos? [Archivo de video]. Recuperado de https://www.youtube.com/ watch?v=zEKUM0DXC4M

Spanish Police. (2017, octubre 01). Spanish Police. Recuperado de https://spanishpolice. github.io/

Varga, S. (2013). 'The politics of nation branding. Collective identity and public sphere in a neoliberal state'. Journal of Philosophy and Social Criticism, 39(8), pp. 825-845.

ThisIsTheRealSpain. (s. f.). ¿Conoces la España de verdad?. Recuperado de https:// espanaglobal.gob.es/

Vasallo, I. (2003, febrero 23). La última obra de Joan Miró. El País. Recuperado de https:// elpais.com/diario/2003/02/23/domingo/1045975961_850215.html 